\title{
SYPHILIS IN RELATION TO THE ETIOLOGY AND DIAGNOSIS OF MALIGNANT DISEASE *
}

By Professor ARCHIBALD LEITCH, M.D.

When he accepted the invitation to address the Society he thought he would be merely one of the speakers in a discussion, and only recently, when receiving the agenda, did he realise that something more was expected of him. He feared he had not a great deal to impart, but he hoped he might learn something from the general discussion.

Remembering how varied were the complications and sequelæ of syphilis, it was not surprising that when the nature of any given disease condition was obscure syphilis should often be invoked either as a predisposing or a contributory factor. There was a suggestion that, as a syphilitic lesion left behind it a soil with diminished resistance to disease, cancer was particularly prone to develop on those situations. Some would go further in maintaining that syphilis predisposed the body to cancer wherever it might localise itself. Parenthetically, so striking was the demonstration of the causal agent in syphilis that some were buoyed up with the hope that a similar (i.e., a microbial or spirochætal) cause might be found in cancer. Naturally, the more deeply rooted the impression was of a close sequential relationship between syphilis and cancer the more frequently would one be able to substantiate this thesis by probing the clinical histories of cases. On the other hand, the Wassermann reaction was a much more impersonal matter, and not so liable to bias. There were always borderline cases, of course, though only comparatively few.

A positive Wassermann reaction did not necessarily mean that any particular lesion found in a syphilitic

* Based on an address delivered before the Medical Society for the Study of Venereal Diseases on April 27th, 1928. 


\section{BRITISH JOURNAL OF VENEREAL DISEASES}

patient was syphilitic. He thought dermatologists were most likely to know whether old syphilitic ulcers frequently became the seats of malignant disease. It was frequently stated in text-books that such was the case, but he would like to learn from his audience whether it was an observed fact or merely an oft-repeated myth. A French writer used these words: "Syphilitic persons are potential candidates for cancer and live for ever beneath a sword of Damocles." Was that so ? He did not believe it.

Dr. H. J. B. Fry during the last three years or so had been accustomed to test the Wassermann reaction of the serum of patients at the Cancer Hospital simultaneously with his own serodiagnostic test. Of $76 \mathrm{I}$ cases of cancer he got a positive Wassermann in 66 , or 8.7 per cent. The diagnosis in all those cases was absolutely certain. It was impossible to say what proportion of the ordinary population gave the positive Wassermann. But in the same hospital, taking those who had simple tumours as well as those who had other lesions that were suspected of being neoplastic in nature, but were proved not to be, 77 out of 720 had a positive Wassermann, or I0.7 per cent. If that were the simple issue, any causal relationship between the two diseases might well be dismissed. Taking the organs of the body separately, however, in certain cases the idea seemed to be somewhat strengthened. In cancer of the cervix I 3.3 per cent. had a positive Wassermann; cancer of the breast, only 2.3 per cent. ; cancer of the rectum, 3 per cent. ; cancer of stomach, 15.4 per cent. ; epithelioma of vulva, 6 per cent.; cancer of the buccal cavity (excluding the tongue), I3.2 per cent. In the tongue 3I per cent. of the cancer cases gave a positive Wassermann. The figures for other sites were too small for one to trust to percentages as an indication of the relationship. From an analysis of cases of cancer of the tongue reported by Cary from Johns Hopkins Hospital, Baltimore, one could calculate that when Wassermann reactions were performed 45.4 per cent. were positive, whilst the cancers of the buccal cavity gave the same percentage as Dr. Fry had found.

As regards the uterus, primary chancre and secondary manifestations and tertiary lesions could be confused with malignant disease. There was no pain, as a rule, in the lesions of syphilis, and in cancer of the cervix pain 


\section{DIAGNOSIS OF MALIGNANT DISEASE}

was often a late symptom. Gelhorne had reported three cases in which advanced syphilitic lesions of the cervix became malignant. Was there a direct transition of the gummatous ulceration to cancer, or was there an intermediate stage of leucoplakia? He did not know any satisfactory statistics to prove that leucoplakia was invariably a syphilitic manifestation. Bruck reported twelve cases of leucoplakia in which the Wassermann was positive in ten. The figures of breast cases gave no support to there being any connection between the two diseases. W. Ernest Miles, with a very large experience of rectal cases, said he had seen only two cases of syphilis of the rectum in his life. One condition of the rectum in women which was usually diagnosed as syphilis, but on which anti-syphilitic remedies had no effect, was a chronic infection of the sacro-uterine ligaments, which as they encircled the rectum compressed it.

The case of cancer of the tongue was of great importance. Dr. Fry's figures gave $3 I$ per cent. positive Wassermann, Carey's 45 per cent., while the late Sir Charles Ryall, with a large experience of both diseases and with facilities for following the cases up, said that the cases of cancer of the tongue giving a history of syphilis were over 80 per cent., a figure which corresponded closely with that of Fournier. It was questionable if syphilis was the only factor in the causation of cancer of the tongue. Ryall attributed much to the effect of smoking on a tongue made sensitive by syphilis. A large series of mice and rats had been treated with tobacco extract; and though the speaker had induced ulcers of the tongue in rats, no malignant growths had developed so far. The skin of these animals did not give any neoplastic reaction to the applications of this tobacco tar, but the mucous membrane of the tongue might be more vulnerable to that kind of tar than the skin. There was an experimental observation of great importance in the relationship between syphilis and cancer. Brown and Pearce, of the Rockefeller Institute, inoculated the scrotum of a rabbit with spirochætes in I9I6, and a chronic inflammation of the scrotum existed for three and a half years. A year later a tumour nodule appeared at the site, which grew rapidly and recurred after removal. After a second recurrence the animal was killed, and metastases were found in the inguinal glands and in many internal organs.

v.D. 


\section{BRITISH JOURNAL OF VENEREAL DISEASES}

It was epithelioma, but of a rather peculiar type, more like Paget's disease. The post-mortem on that rabbit disclosed lesions of the dermis of a sclerodermatous kind, cardio-vascular lesions, and lesions of the tongue and buccal cavity with downgrowths of epithelium. It might be concluded that sometimes the spirochæte might act as a carcinogenic agent, but probably the process was much less direct. 